\title{
DEFORMAÇÃO E METAMORFISMO DAS SEQÜÊNCIAS JUSCELÂNDIA E SERRA DA MALACACHETA, COMPLEXO BARRO ALTO, GOIÁS
}

\author{
RENATO DE MORAES*, REINHARDT A. FUCK
}

\begin{abstract}
DEFORMATION AND METAMORPHISM OF THE JUSCELÂNDIA AND SERRA DA MALACACHETA SEQUENCES, BARRO ALTO COMPLEX, GOIÁS. The Juscelândia volcanosedimentary and the Serra da Malacacheta gabbro-anorthositic sequences are part of the Barro Alto Complex, central Goiás, Brazil. In a geological section from south to north, the following tectonic-stratigraphic succession is recognized: i) mafic to felsic granulites, ii) sillimanite-garnet quartzite, iii) banded garnet amphibolite, iv) fine grained (garnet) amphibolite (metabasalt) with intercalations of metachert and calcsilicate rocks, $v$ ) biotite granite gneiss (metagranitoid) cut by fine grained (garnet) amphibolite dykes, vi) biotite-muscovite gneiss, feldspathic schist and micaschist (felsic volcanics, tuffs), vii) schist and phyllite with minor amphibolite and biotite-muscovite gneiss. Units $i$ and ii represent the Serra de Santa Bárbara sequence, unit iii represents the Serra da Malacacheta sequence, whereas units iv to vii are included in the Juscelândia sequence. Four phases of deformation were recognized, the first two generated in a progressive event, while the last phases are represented by open folds and associated with retrometamorphic greenschist facies recristallization. The main foliation (Sn), formed by amphibolite facies minerals, strikes EW and dips $55^{\circ}$ to the N. The associated stretching lineation is parallel to the strike of the main foliation and plunges slightly to the west. Along with kynematic indicators, this relationship indicates that the structures were formed in a lateral ramp of a major thrust structure, with tectonic transport from west to east. Garnet, staurolite and kyanite porphyroblasts overgrow the main foliation in micaschists, indicating that the peak of metamorphism post-dates the main deformation. The metamorphism of the Juscelândia sequence occurred at $520^{\circ} \mathrm{C}$ and $5.5 \mathrm{kbar}$, while in the Serra da Malacacheta sequence metamorphic conditions reached $720^{\circ} \mathrm{C}$ and $8.5 \mathrm{kbar}$. Textural relationships in micaschists of the Juscelândia sequence indicate a clockwise PT path of metamorphism.
\end{abstract}

Keywords: metamorphism, lateral ramp, Juscelândia sequence, Serra da Malacacheta Sequence, Barro Alto Complex.

\begin{abstract}
RESUMO As seqüências Juscelândia e Serra da Malacacheta fazem parte do Complexo Barro Alto, localizado na porção central do Estado de Goiás. Em uma seção geológica de sul para norte, a seguinte sucessão tectonoestratigráfica é reconhecida: i) granulitos máílcos a félsicos, ii) sillimanita-granada quartzito, iii) (granada) anfibolito bandado, iv) (granada) anfibolito fino (metabasalto) com intercalações de metacherte e rochas calcissilicáticas, v) biotita gnaisse granítico (metagranitóide) cortado por diques de (granada) anfibolito fino, vi) gnaisse, xisto feldspático e mica xisto (vulcânica félsica e tufo), vii) xisto e filho com intercalações de anfibolito e biotitamuscovita gnaisse. As unidades i e ii representam a seqüência Serra de Santa Bárbara, a unidade iii representa a seqüência Serra da Malacacheta, enquanto que as unidades iv até vii são incluídas na seqüência Juscelândia. Quatro fases de deformação foram reconhecidas. As duas primeiras foram geradas em um evento progressivo e são responsáveis pela implantação da foliaçãp principal (Sn), de dobras fechadas e uma lineação direcional (Ln). Sn é definida por minerais de fácies anfibolito e possui direção $\mathrm{EW}$, mergulhando $55^{\circ}$ para norte. A lineação de estiramento associada tem caráter direcional e caimento suave para oeste. Os indicadores cinemáticos e a relação entre a foliação principal e a lineação de estiramento indicam que as estruturas foram geradas em uma rampa lateral de uma estrutura maior de cavalgamento, com transporte tectônico para leste. As outras duas fases de deformação são responsáveis por dobras abertas associadas com recristalização de fácies xisto verde. Porfiroblastos de granada, estaurolita e cianita sobrecrescem Sn, indicando que o pico do metamorfismo foi tardio em relação à deformação principal. As condições do metamorfismo que afetou as rochas da seqüência Juscelândia foram calculadas em $520^{\circ} \mathrm{C}$ e $5,5 \mathrm{kbar}$, enquanto as condições para as rochas da seqüência Serra da Malacacheta alcançaram $720^{\circ} \mathrm{C}$ e 8,5 kbar. As relações texturais dos minerais dos micaxistos da seqüência Juscelândia indicam um padrão PT horário para o metamorfismo.
\end{abstract}

Palavras-chave: metamorfismo, rampa lateral, seqüência Juscelândia, seqüência Serra da Malacacheta, Complexo Barro Alto.

INTRODUÇ̃̃O O Complexo Barro Alto, situado na porção central do Estado de Goiás, apresenta a forma de um "bumerangue", com um segmento de direção EW e outro de direção NE, que, em conjunto, têm uma extensão aproximada de $150 \mathrm{~km}$ (Figura 1). Junto com os complexos Niquelândia e Cana Brava, o Complexo Barro Alto faz parte de uma extensa faixa descontínua de rochas de médio a alto grau metamórfico, que representa a borda oriental do Maciço de Goiás (Fuck 1994).

Os três complexos possuem estratigrafia semelhante. A porção basal é representada por rochas acamadadas granulitizadas, as quais estão em contato tectônico com as rochas do embasamento granito-gnáissico através de falhas inversas (Fuck et al. 1981, Ferreira Filho \& Naldret 1991, Correia
1994). Os granulitos são sobrepostos pelas seqüências gabro-anortosíticas Serra da Malacacheta, no Complexo Barro Alto, e Serra dos Borges, no Complexo Niquelândia (Fuck et al. 1981, Danni \& Leonardos 1980). Rochas similares são encontradas no Complexo Cana Brava (Ribeiro Filho $\&$ Teixeira 1981).

Às rochas gabro-anortosíticas sobrepõem-se seqüências vulcano-sedimentares. Sobre a seqüência Serra da Malacacheta expõe-se a seqüência Juscelândia reconhecida originalmente na região de Goianésia (Fuck et al. 1981), de onde se estende até Ceres-Rubiataba (Danni et al. 1984). A oeste da seqüência Serra dos Borges e dela separada por uma extensa zona de cisalhamento dextral dispõe-se a seqüência Coitezeiro (Brod 1988), originalmente definida como 


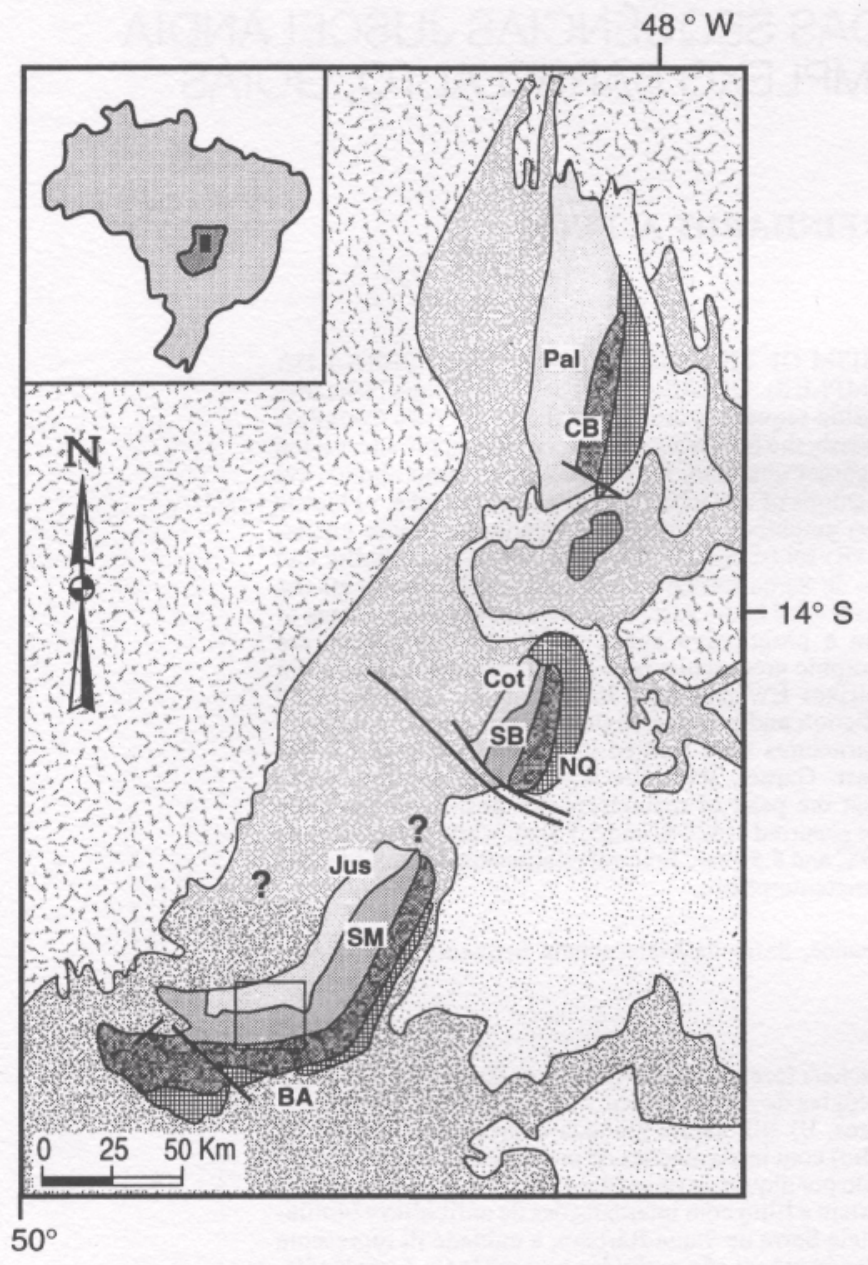

\section{Legenda}

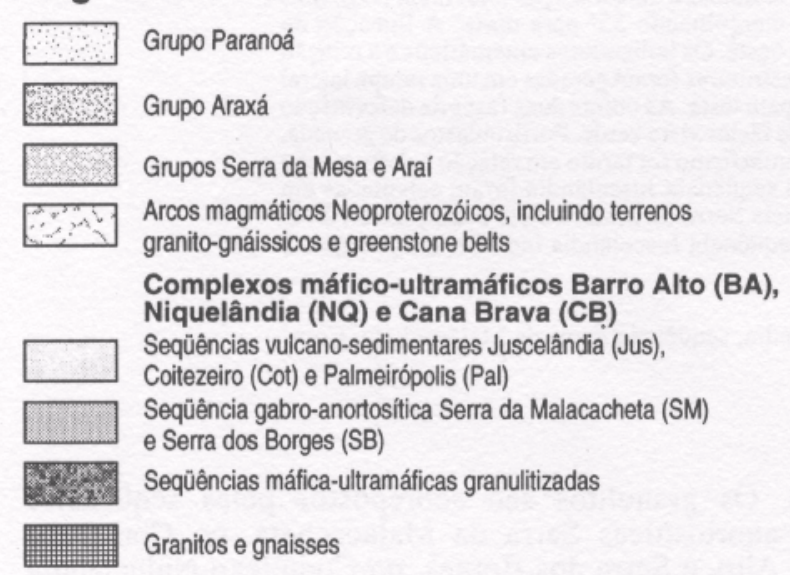

Área da figura 2

Figura 1 -Esboço regional da porção centro-sul da Província Tocantins (modificado a partir de Fuck et al. 1987) Figure 1 - Regional sketch map of central-southern Tocantins Province (modified after Fuck et al. 1987)

Indaianópolis (Danni \& Leonardos 1980). No Complexo Cana Brava a seqüência vulcano-sedimentar foi denominada de Palmeirópolis (Ribeiro Filho \& Teixeira 1981, Araújo 1986).
A origem dos complexos é objeto de controvérsia. Muitos pesquisadores defendem a hipótese de que as rochas dos complexos representariam intrusões acamadadas, como Bushveld ou Stillwater (Pecora \& Barbosa 1944, Milewski et al. 1970, Girardietal. 1981, 1986, Oliveira \& Jost 1992), subseqüentemente deformadas e metamorfizadas (Fleischer \& Routhier 1970, Stache 1976, Ferreira Filho \& Naldret 1991). Diversos autores postulam uma origem ofiolítica para os complexos (Almeida 1967, Angeiras 1968, Costa \& Angeiras 1971) ou para pelo menos parte deles (Danni \& Leonardos 1980, Danni \& Kuyumjian 1984, Kuyumjian \& Danni 1991, Moraes 1992). Em alguns trabalhos, foi sugerido que os complexos formariam uma nova categoria, de complexos pseudo-estratiformes, por não possuírem características típicas de grandes intrusões (Motta et al 1972, Baeta Jr et al 1972, Thayer 1972, Figueiredo 1978).

A idade dos complexos é também controversa. Por algum tempo, pensava-se que a porção basal dos complexos fosse arqueana, enquanto as seqüências gabro-anortosíticas e vuicano-sedimentares seriam do Proterozóico inferior (Danni \& Leonardos 1980, Fuck et al 1981). Dados geocronológicos obtidos pelo método $\mathrm{Rb}-\mathrm{Sr}$, em rocha total em granulitos félsicos do Complexo Barro Alto e em gnaisses da seqüência Juscelândia, forneceram idades em torno de $1300 \mathrm{Ma}$, interpretadas como representativas de recristalização metamórfica durante o Mesoproterozóico, associada a uma colisão continental (Fuck et al 1988, 1989).

As idades U-Pb indicam uma história diferente para os complexos Niquelândia e Barro Alto. No Complexo Niquelândia, foram datados meta-anortositos, quartzo diorito e blastomilonitos ricos em quartzo. As discórdias obtidas apontam para um intercepto superior de $1583 \pm 25 \mathrm{Ma}$ nos anortositos e de $1565 \pm 22 \mathrm{Ma}$ em quartzo diorito. Os interceptes inferiores, englobando os resultados dos blastomilonitos, ficaram no intervalo entre 770 a $795 \mathrm{Ma}$. As idades do Mesoproterozóico foram interpretadas como correspondentes ao posicionamento magmático da intrusão acamadada de Niquelândia e as do Neoproterozóico são relacionadas ao metamorfismo que a afetou (Ferreira Filho \& Naldrett 1991, Ferreira Filho et al 1994).

Os primeiros dados U-Pb para o Complexo Barro Alto indicam valores semelhantes aos de Niquelândia. Foram datados granada-quartzo diorito da seqüências Serra de Santa Bárbara, granada-sillimanita gnaisse posicionado tectonicamente na unidade e um gabro pegmatóide da seqüência Serra da Malacacheta. A idade do intercepto superior do granada-quartzo diorito é cerca de 1.72-1.73 Ga e do gabro pegmatóide 1.29-1.35 Ga. Esses valores são interpretados como idade de intrusão e de magmatismo tardio do Complexo Barro Alto. As idades de intercepto inferior do granadasillimanita gnaisse ficaram no intervalo entre $0.7-0.82 \mathrm{Ga}$ e são consideradas como idade do metamorfismo (Suita et al 1994).

No presente trabalho é detalhada a geologia das seqüências Juscelândia e Serra da Malacacheta, sua evolução estrutural e metamórfica. A área investigada situa-se a noroeste da cidade de Goianésia, englobando as localidades de Juscelândia, Cafelândia e Ponte Alta (Figura 2).

AS ROCHAS METAMÓRFICAS DA REGIÃO DE JUSCELANDIA-CAFELÂNDIA $\mathrm{Na}$ área estudada, afloram rochas metamórficas derivadas de protolitos plutônicos, vulcânicos e sedimentares. As diferentes unidades litológicas estão dispostas em faixas ou extensos corpos lenticulares de direção geral EW.

Em uma seção geológica de sul para norte, é reconhecida a seguinte sucessão (Figura 2):

- uma faixa composta de rochas granulíticas pertencentes à seqüência granulítica Serra de Santa Bárbara; 


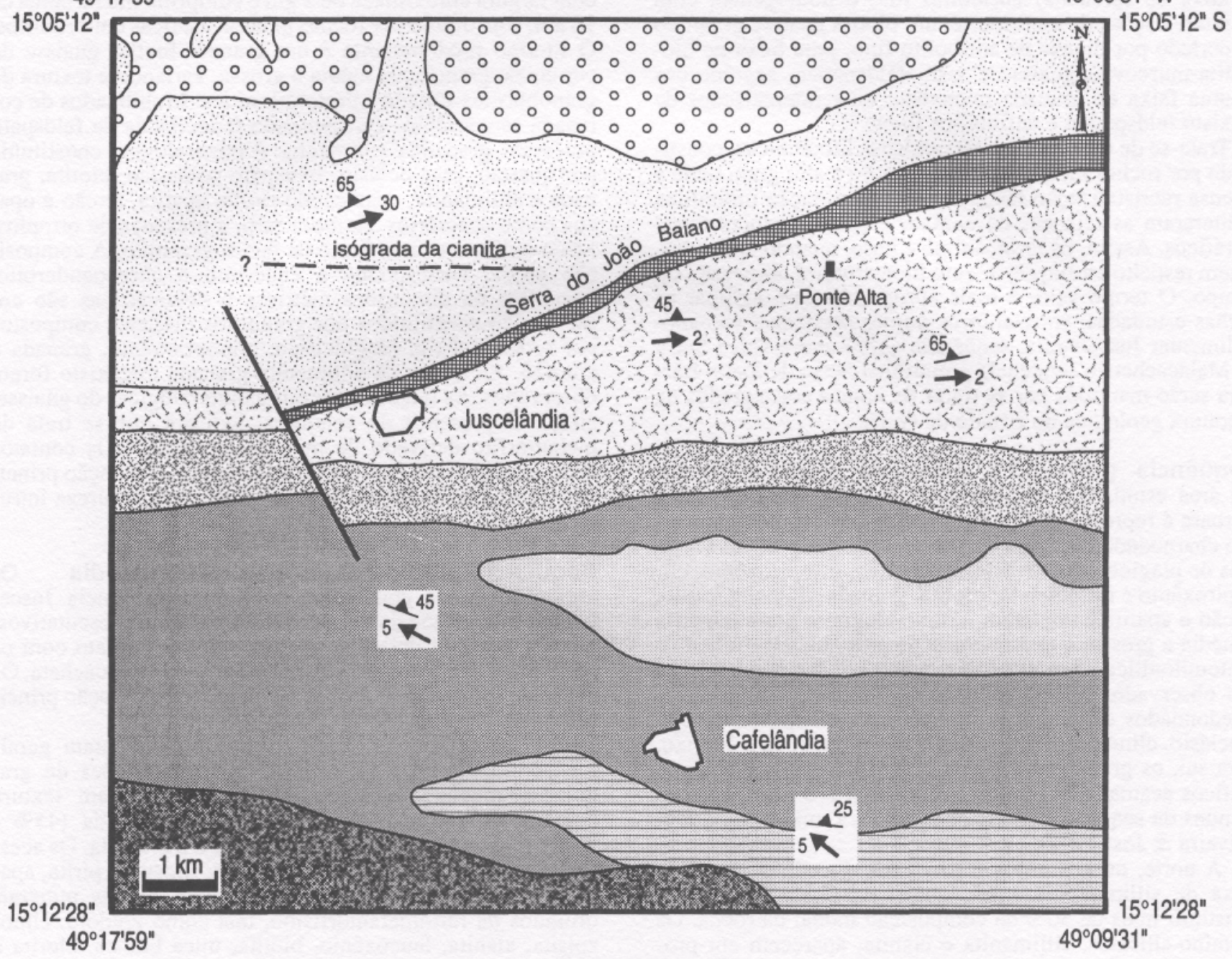

\section{Legenda}

\section{Cobertura laterítica}

\section{Seqüência Vulcano-sedimentar Juscelândia}

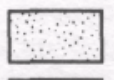
Estaurolita-granada micaxisto com cianita/fibrolita, e com intercalaçőes de anfibolito e metacherte Biotita-muscovita gnaisse com intercalações de granada anfibolito

Biotita gnaisse granítico cortado por diques de granada anfibolito

Hitwe Granada anfibolitos com metacherte

A Foliação

k Lineação mineral (orientação/estiramento)

\section{Seqüência Serra da Malacacheta}

Granada anfibolito bandado

Gnaisse granulítico com xenólitos de rochas básicas

\section{Seqüência Granulítica Serra de Santa Bárbara}

Sillimanita-granada quatzito e granada granulitos félsicos e máficos

Granada gnaisse enderbítico a charnoenderbítico e metagabro-norito

Falha

Contato geológico

Figura 2-Mapa geológico da região de Juscelândia - Cafelândia (modificado de Moraes 1992, Universidade de Brasília 1980)

Figure 2 - Geological map of the Juscelândia - Cafelândia region (modified from Moraes 1992, Universidade de Brasília 1980) 
- uma faixa de anfibolitos bandados, incluídos na seqüência Serra da Malacacheta, em cujo interior se expõe um corpo lenticular de gnaisse granulítico;

- a seqüência Juscelândia, em que é discriminada uma faixa de (granada) anfibolito fino e homogêneo, com intercalações de metacherte, um biotita gnaisse granítico cortado por diques de anfibolito fino, uma faixa de biotita-muscovita gnaisse e xisto feldspático, seguida por uma faixa de granada micaxisto, com intercalações de xisto feldspático e anfibolitos finos.

Trata-se de um conjunto de unidades litodêmicas, constituído por rochas metamórficas de médio a alto grau, onde a intensa recristalização metamórfica e a foliação milonítica obliteraram as relações de contato e os indicadores estratigráficos. Assim, os termos topo e base, quando aplicados, dizem respeito ao empilhamento litoestrutural observado no campo. O termo suite é mais apropriado para agrupar as rochas estudadas, entretanto os nomes seqüência vulcanosedimentar Juscelândia, seqüência gabro-anortosítica Serra da Malacacheta e seqüência granulítica Serra de Santa Bárbara serão mantidos por se tratar de nomes consagrados na literatura geológica do Estado de Goiás.

\section{Seqüência granulítica Serra de Santa Bárbara}

$\mathrm{Na}$ área estudada a seqüência granulítica Serra de Santa Bárbara é representada por granulitos félsicos de composição charnoenderbítica a enderbítica, com proporções variáveis de plagioclásio, ortoclásio, quartzo, ortopiroxênio, clinopiroxênio e hornblenda; biotita, granada, ilmenita, rutilo, zircão e apatita completam a mineralogia; a granulometria é média a grossa; a textura varia de granoblástica foliada a protomilonítica. Xenólitos das mais variadas composições são observados nessas rochas, predominando fragmentos arredondados de granulito máfico fino, composto de plagioclásio, clinopiroxênio, ortopiroxênio, granada e quartzo. Para sul, os granulitos félsicos cedem lugar aos granulitos máficos acamadados, que correspondem aos litotipos mais comuns da seqüência (Fuck et al. 1981, Danni et al. 1984, Oliveira \& Jost 1992).

A norte, os granulitos félsicos são sucedidos por uma faixa de sillimanita-granada quartzito. Granada chega a constituir mais de $30 \%$ da composição modal da rocha. Os alumino-silicatos, sillimanita e cianita, aparecem em proporções reduzidas; em alguns afloramentos a sillimanita pode atingir mais de $10 \mathrm{~cm}$.

\section{Seqüência gabro-anortosítica Serra da Malacacheta}

Na região centro-meridional da área enfocada, estão expostos (granada) anfibolitos bandados, atribuídos à seqüência Serra da Malacacheta (Fuck et al. 1981, Moraes 1992). A leste, os anfibolitos dão lugar a um conjunto de rochas plutônicas acamadadas, com olivina gabros coroníticos, troctolitos e anortositos (Fuck et al 1981).

Os anfibolitos apresentam granulação média, cor verde escura a preta e bandamento composicional centimétrico a decimétrico. As bandas são descontínuas e boudinadas, às vezes mostrando dobras apertadas ou intrafoliais, sem raiz, com a foliação principal em posição plano axial. A rocha é constituída por hornblenda e plagioclásio; quartzo, clinopiroxênio e granada podem estar presentes. Os acessórios são ilmenita, magnetita, titanita, apatita e zircão. Cristais de ortopiroxênio são encontrados em alguns afloramentos; em geral, são alongados, apresentam lamelas de exsolução e kink bands. Essas feições são semelhantes aos remanescentes ígneos dos granulitos máficos da seqüência Serra de Santa Bárbara, e, por isso, interpretados como reliquiares. Os anfibolitos bandados expostos entre os sillimanita-granada quartzitos e os granulitos a sudoeste de Cafelândia (Figura 2), contem ortopiroxênio em cristais equidimensionais, límpidos e com junções tríplices típicas de grãos metamórficos. Clinozoisita, epidoto, carbonato, biotita, mica branca, clorita e leucoxênio são minerais oriundos de retrometamorfismo.

A norte de Cafelândia, expõe-se um corpo lenticular, com largura aproximada de $2 \mathrm{~km}$ e comprimento de cerca de $10 \mathrm{~km}$, constituído por rochas gnáissicas, ricas em xenólitos. O litotipo predominante é um granada-biotita gnaisse de cor cinza, granulação média a grossa, variando a textura de granoblástica foliada a protomilonítica. Mobilizados de cor rosada são comuns, apresentando fenocristais de feldspato potássico, granada e sillimanita. A mineralogia é constituída por quartzo, plagioclásio, feldspato potássico, biotita, granada e sillimanita, aparecendo rutilo, apatita, zircão e opacos como acessórios. Embora raro, a presença de ortopiroxênio indica metamorfismo de facies granulito. A composição modal corresponde a enderbito e charnoenderbito. Xenólitos de dimensões métricas a decimétricas são comuns. São constituídos por granulitos máficos, compostos por ortopiroxênio, plagioclásio, clinopiroxênio, granada e quartzo. Xenólitos de sillimanita-granada micaxisto foram observados. As feições texturais e mineralógicas do gnaisse, aliadas à presença de xenólitos, indicam que se trata de metamorfíto derivado de material plutônico. Os contatos com os anfibolitos bandados são paralelos à foliação principal, não tendo sido possível comprovar sua natureza intrusiva original.

\section{Seqüência vulcano-sedimentar Juscelândia}

Os

anfibolitos finos constituem a base da seqüência Juscelândia. Em virtude da falta de afloramentos representativos, não foi possível definir a natureza do seu contato com os anfibolitos bandados da seqüência Serra da Malacacheta. Os dados de campo indicam que são paralelos à foliação principal.

Os anfibolitos são verde escuros e apresentam geralmente granulação fina, embora existam porções de granulação média; são homogêneos e apresentam textura nematoblástica. São constituídos de hornblenda (45\% $70 \%$ ), plagioclásio $(25 \%-45 \%)$, quartzo e granada. Os acessórios são titanita (até 4\%), magnetita, ilmenita, pirita, apatita e esporadicamente zircão. Ocorrem alguns minerais oriundos de retrometamorfismo, tais como epidoto, clinozoisita, alanita, leucoxênio, biotita, mica branca, clorita e carbonato.

As intercalações de metachertes são representadas por granada quartzitos finos, de cor preta. Formam lentes métricas entre os anfibolitos finos. Rochas calcissilicáticas foram identificadas em dois afloramentos. Em um deles a rocha é preta, de granulação fina, composta por hornblenda e quartzo; plagioclásio, granada, apatita, opacos, titanita e alanita são acessórios. No outro, a rocha é de cor cinza claro, de granulação média-grossa, com porfiroblastos de clinopiroxênio em matriz granoblástica, constituída de diopsídio, epidoto, plagioclásio, zoisita e titanita.

A total recristalização metamórfica dos anfibolitos não permite o reconhecimento de texturas ígneas; no entanto, a sua homogeneidade textural e química (Moraes, 1992) e, no campo, a sua íntima relação com metachertes e rochas calcissilicáticas indicam tratar-se de metabasaltos extrudidos em ambiente subaquoso.

A norte dos anfibolitos finos está exposta uma ampla faixa constituída por biotita gnaisse granítico. Apresenta cor cinza claro e granulação média. A foliação é anastomosada, sendo comum a presença de cordões de quartzo e feldspato, bem como uma forte lineação mineral marcada por biotita e muscovita. Localmente, ocorre a diminuição da granulometria, devida à intensa deformação, conferindo à rocha textura milonítica. Uma das características mais marcantes dessa rocha é a sua homogeneidade textural e mineralógica. Essa feição, somada à presença eventual de apófises cortan- 
do os anflbolitos, levou à conclusão de que o biotita gnaisse granítico é derivado de rochas plutônicas de composição granítica, intrusivas na pilha vulcano-sedimentar. Entretanto, em boa parte dos afloramentos o gnaisse é cortado por diques de anfibolitos finos, os quais apresentam bordas de resfriamento preservadas e feições de assimilação do gnaisse, evidenciando que o magmatismo básico foi, em parte, hipoabissal. Os diques foram deformados e paralelizados à foliação (Foto 1).

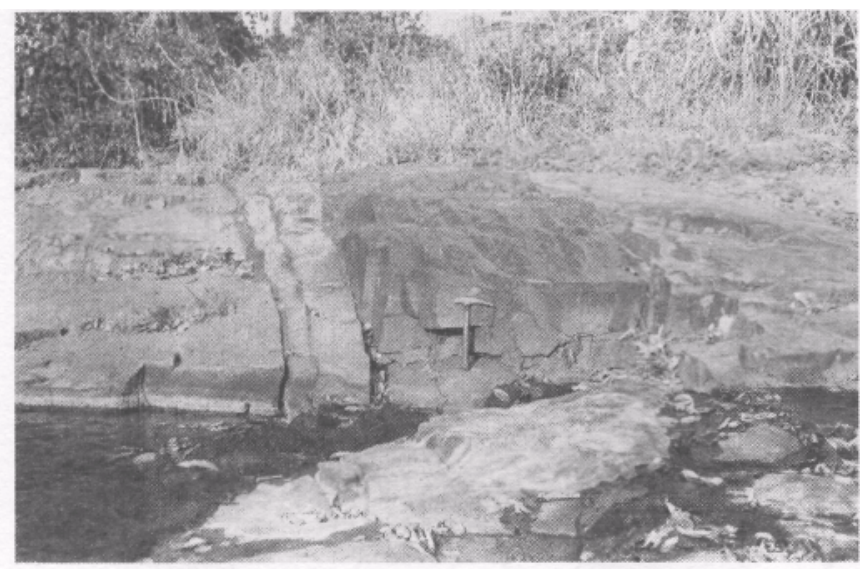

Foto 1 - Dique de anfibolito fino (indicado pelo martelo) encaixado em biotita gnaisse granítico da sequência Juscelândia

Photo 1 - Fine grained amphibolite dyke (shown by hammer) intruded in biotite granite gneiss of the Juscelândia sequence

A norte de Juscelândia e Ponte Alta, a Serra do João Baiano é sustentada por uma camada de biotita-muscovita gnaisse. $\mathrm{O}$ gnaisse tem cor cinza claro e sua granulação varia de fina a média. A variação pode conferir à rocha um bandamento granulométrico e até composicional, milimétrico a centimétrico. Além do bandamento, observam-se grãos milimétricos ovalados de quartzo azulado, com feições sugestivas de golfo de corrosão (Foto 2), porfiroclastos de feldspato e alguns fragmentos de rocha. Afloram também muscovita xistos feldspáticos, sugerindo uma variação relacionada aos protolitos da unidade. Os xistos feldspáticos e os gnaisses têm textura granoblástica, passando a lepidoblástica nos leitos mais ricos em filossilicatos; muitas vezes a textura é milonítica. A variação granulométrica e textural, a presença de fragmentos de rocha e a identificação de grãos de quartzo com golfos de corrosão, são indicativos de que a unidade é composta por rochas vulcanoclásticas, possivelmente tufos a cristal, tufos líticos e tufos cineríticos. O biotita-muscovita gnaisse é portador de disseminações de sulfetos constituídos de pirita, pirrotita, esfalerita e galena. Em alguns lugares da Serra do João Baiano foram observados chapéus de ferro, que podem indicar a presença de lentes de sulfetos em profundidade. A área foi prospectada pela Mineração Itaimbé que identificou depósitos de sulfetos maciços de metais básicos.

A unidade mais setentrional da seqüência Juscelândia é dominada por micaxistos, que contem intercalações esporádicas de (granada) anfibolito fino e xistos feldspáticos, similares aos descritos nos pacotes sotopostos. Embora ocorram variações na composição modal, a rocha mais comum é granada-muscovita-biotita xisto. Minerais opacos, apatita, zircão e turmalina são os principais acessórios. Estaurolita é amplamente distribuída, lateral e verticalmente no pacote, diminuindo sua concentração em direção ao topo e para nordeste, enquanto a cianita apresenta distribuição restrita, ocorrendo só a norte-nordeste de Juscelândia. Cordierita e fibrolita foram constatadas localmente. A leste da área estudada, os xistos parecem gradar, vertical e lateralmente, para filitos, constituídos por muscovita, clorita e quartzo, sendo comum a presença de matéria carbonosa.

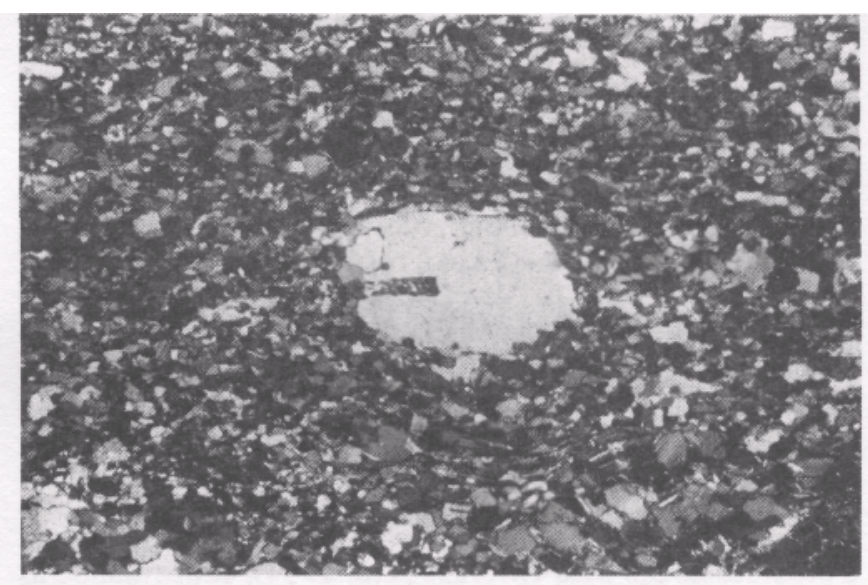

Foto 2 - Grão de quartzo com golfo de corrosão atestando a natureza vulcânica do protolito do biotita-muscovita gnaisse (Aumento 10x)

Photo 2 - Corroded quartz grain in biotite-muscovite gneiss, indicating the volcanic nature of the protolith (Enlargement 10x)

METAMORFISMO O metamorfismo que afetou as rochas do Complexo Barro Alto foi caracterizado como do tipo barroviano, variando da fácies granulito na seqüência Serra de Santa Bárbara, para a fácies anfibolito nas seqüências Serra da Malacacheta e Juscelândia, no topo da qual as condições teriam sido da fácies xisto verde (Fuck et al. 1981).

A transição aparente observada no campo não é suportada pelos valores preliminares de temperatura e pressão, calculados a partir de análises químicas de minerais obtidas em microssonda eletrônica. Os dados revelam a existência de diferenças marcantes entre as associações minerais das seqüências Serra da Malacacheta e Juscelândia (Moraes et al. 1994).

O anfibolito Serra da Malacacheta é constituído por hornblenda + plagioclásio $\left(\mathrm{An}_{40-42}\right)+$ opacos \pm quartzo \pm clinopiroxênio(Wo $\left.\mathrm{W}_{4649}, \mathrm{En}_{29-32}, \mathrm{FS}_{19 \cdot 23}\right) \pm$ granada $\left(\mathrm{Alm}_{57-65}, \mathrm{Py}_{7-12}\right.$, $\left.\mathrm{Gr}_{8-30}, \mathrm{Sp}_{4-6}\right) \pm$ titanita. Ortopiroxênio metamórfico ocorre apenas a sudoeste de Cafelândia, na porção onde as rochas da seqüência Serra da Malacacheta estão sobrepostas pelo sillimanita-granada quartzito. Nelas não há quartzo coexistente.

Apesar de descritas no campo como anfibolitos, algumas das suas bandas apresentam paragêneses granulíticas de pressão elevada, caracterizadas pela associação granada + clinopiroxênio + quartzo (Yardley 1989). A paragênese pode ter sido gerada pela reação

4 ortopiroxênio $($ relícto ígneo $)+$ plagioclásio $=$ granada + clinopiroxênio + quartzo .

A reação para a formação do ortopiroxênio metamórfico pode ter sido

quartzo + granada $=2$ ortopiroxênio + plagioclásio (Yardley 1989).

Nos gnaisses granulíticos associados ocorre a paragênese sillimanita + feldspato potássico e mobilizados com sillima- 
nita + granada como restito, envolvendo aparentemente as seguintes reações na sua geração:

muscovita + quartzo = K-feldspato + sillimanita + fusão;

biotita + sillimanita + quartzo $=$ K-feldspato + granada + fusão (Yardley 1989).

$\mathrm{O}$ anfibolito indica que as condições do metamorfismo alcançaram a transição entre as fácies anfibolito e granulito, o que é corroborado pelas paragêneses do gnaisse granulítico, indicando que o metamorfismo ocorreu acima da curva de fusão dos granites e, provavelmente, da segunda isógrada da sillimanita. Essa inferência é sustentada pelos dados preliminares de temperatura e pressão para a unidade, calculados em $720^{\circ} \mathrm{C}$ e 8,5 kbar, respectivamente (Moraes et al 1994).

Os anfibolitos da seqüência Juscelândia são caracterizados pela associação mineral hornblenda + plagioclásio $\left(\mathrm{An}_{92.97}\right)+$ opacos \pm quartzo \pm granada $\left(\mathrm{Alm}_{65-67}, \mathrm{Py}_{8-12}\right.$, $\left.\mathrm{Gr}_{14-19}, \mathrm{Sp}_{6}\right) \pm$ titanita. Nas mais de trinta lâminas delgadas estudadas não foi constatada a presença de piroxênios nessas rochas. Os dados preliminares de geotermobarometria dos anfibolitos Juscelândia indicam temperaturas de $520^{\circ} \mathrm{C}$ e pressões de 5,5 kbar (Moraes et al. 1994), confirmando as estimativas feitas através da petrografia.

Nos xistos associados, a coexistência de cianita e estaurolita indica condições mínimas próximas a $550^{\circ} \mathrm{C}$ e $5,5 \mathrm{kbar}$ (Barker, 1990). A formação da sillimanita está relacionada com a quebra da estaurolita, pela reação

estaurolita + muscovita + quartzo $=$ granada + biotita + sillimanita

que ocorre em temperaturas maiores que $500^{\circ} \mathrm{C}$ (Carmichael 1978).

A cianita possui distribuição restrita na área estudada e o traçado aproximado da sua isógrada é apresentado na figura 2. O intemperismo dos xistos impediu o maior detalhamento do seu contorno. A isógrada da estaurolita aparentemente passa a leste da área mapeada; o seu traçado é dificultado pela variação composicional dos xistos nessa região, onde o mineral ocorre em delgadas camadas de composição apropriada, nem sempre detectadas no campo.

Em um único afloramento de xisto da seqüência Juscelândia foi observada a associação mineral quartzo + biotita + granada + estaurolita + cianita + sillimanita + cordierita. O exame petrográfico indica que a sillimanita é precedida pela cianita e, como em outras amostras, advém da quebra da estaurolita. A cordierita é uma fase tardia, englobando todos os outros minerais aluminosos e ferro-magnesianos, como cianita, sillimanita, estaurolita e granada. Dadas as relações texturais, a presença da cordierita pode ser interpretada como conseqüência de um soerguimento da seqüência Juscelândia para porções crustais mais rasas, porém sem muita perda de calor, favorecendo a formação de um mineral de pressão mais baixa (Yardley 1989), mas ainda sob temperaturas da fácies anfibolito.

No topo da seqüência Juscelândia afloram alguns xistos e filitos ricos em mica branca, contendo clorita, com opacos e turmalina como acessórios. Em alguns afloramentos os filitos são carbonosos. A associação indica que o metamorfismo decresce para o topo da seqüência, passando para as condições da fácies xisto verde.

GEOLOGIA ESTRUTURAL Diversas estruturas estão presentes nas rochas estudadas. A principal é uma foliação penetrativa (Sn), com direção próxima de EW e mergulho mediano $\left(50^{\circ}-60^{\circ}\right)$ para $\mathrm{N}$, acompanhada por uma lineação direcional de estiramento ou mineral. O conjunto é afetado por duas fases de dobramento, orientadas nas direções NNW e EW. São registradas fraturas e zonas de cisaIhamento empinadas.
A Fase Fn-1 Nas dobras onde a foliação principal (Sn) está em posição plano axial, a estrutura afetada é uma foliação pretérita (Sn-1). Do ponto de vista descritivo, as duas foliações são muito semelhantes, tanto no aspecto mineralógico, quanto estrutural. No entanto, não foram observadas dobras, lineações ou outras estruturas que pudessem ser correlacionadas à geração de Sn-1.

A Fase Fn A estrutura de maior penetratividade é uma foliação, identificada pelo símbolo Sn. Embora possua direção geral ENE, com mergulho para NNW, observa-se uma dispersão significativa na sua atitude. Na seqüência Juscelândia, o mergulho varia entre $\mathrm{N}$ e $\mathrm{NW}$, enquanto na seqüência Serra da Malacacheta ele é predominante para N; a média das medidas é respectivamente N65E/50NE e N80E/ $50 \mathrm{NW}$. A diferença pode ser observada nos estereogramas com as freqüências de Sn (Figura 3).
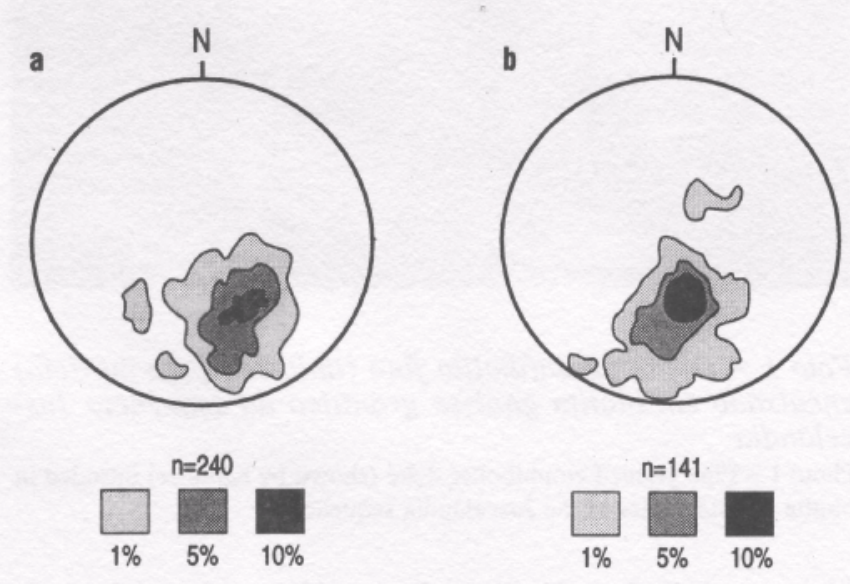

Figura 3 - Estereogramas de freqüência a) pólos da foliação Sn na seqüência Juscelândia, $n=240$, média N65E/ $50 N W ; b)$ pólos da foliação Sn na seqüencia Serra da Malacacheta, $n=141$, média N80E/50NW. Diagrama Schmidt Lambert, hemisfério inferior

Figure 3 - Frequence stereographic projections: a) Sn foliaton poles of the Juscelândia sequence, $\mathrm{n}=240$, average $\mathrm{N} 65 \mathrm{E} / 50 \mathrm{NW}$; b) $\mathrm{Sn}$ foliaton poles of the Serra da Malacacheta sequence, $\mathrm{n}=141$, average N80E/50NW; Schmidt Lambert equal area diagram, lower hemisphere

Enquanto nos anfibolitos a foliação Sn pode ser definida como uma xistosidade (Hobbs et al. 1976), nos gnaisses ela apresenta uma maior variação de texturas. Ao microscópio, a foliação dos gnaisses da seqüência Juscelândia é caracterizada como uma xistosidade anastomosada, com estruturas tipo SC (tectonito tipo LS) e texturas protomiloníticas a ultramiloníticas (Mawer 1986, Wise et al. 1984), podendo até dar lugar a tectonitos tipo L (Davis 1984).

Nas dobras em que Sn se posiciona no plano axial, ocorre a crenulação de uma foliação pretérita (Sn-1), o que é observado principalmente nos xistos e filitos. Em afloramento de xisto feldspático, na porção leste da área mapeada, $\mathrm{Sn}-1$ é definida por biotita parda de granulação fina, rotacionada até a posição de $\mathrm{Sn}$, esta definida por biotita castanha de granulação mais grossa, contendo inclusões de quartzo paralelas a Sn-1. O aumento da granulação sugere um aumento do metamorfismo de $\mathrm{Sn}-1$ para $\mathrm{Sn}$, corroborado pelo sobrecrescimento da foliação por porfiroblastos de granada. Sn parece ter sido gerada a partir do desenvolvimento progressivo de Sn-1, que, após ter sido formada, sofreu uma rotação próxima ao plano de cisalhamento, sendo cortada pela foliação Sn que a sucede. Como as condições de temperatura eram provavelmente mais elevadas, a nova foliação (Sn), que se colocou em posição plano axial da crenulação, é mais 
proeminente. Essa feição parece ter sido gerada em ambiente de deformação progressiva. Sn-1 representaria um estágio precoce da foliação, que, em estágio subsequente, evoluiria para Sn (Williams 1978, Bell \& Hammond 1984, Jacobson 1984).

Durante a formação de Sn, foram desenvolvidas dobras que deformaram $\mathrm{Sn}-1$ e o bandamento presente em algumas rochas. As dobras são intrafoliais, sem raiz e fechadas. As charneiras são cilíndricas e arredondadas em todos os segmentos aflorantes. Nos anfibolitos bandados ocorrem dobras abertas e desarmônicas. Nos xistos, muitas delas são agudas. $\mathrm{O}$ espessamento apical e o adelgaçamento de flancos é comum; falhas paralelas ao plano axial são desenvolvidas esporadicamente.

Dois tipos de lineações estão associados a Sn. O primeiro é uma lineação direcional de estiramento ou mineral (Ln), enquanto o outro é constituído pelos eixos das dobras Dn.

A lineação Ln é facilmente reconhecida no campo e caracterizada como de estiramento, devido à formação de fitas e bastões de quartzo e feldspatos e de anfibólios microboudinados. As medidas da atitude de Ln estão representadas na figura 4. A partir dos estereogramas, pode ser visto que a lineação tem direção WNW a WSW e ENE, com caimento sub-horizontal para W e ENE; as medidas médias respectivas são $\mathrm{N} 85 \mathrm{~W} / 25$ para a seqüência Juscelândia e $\mathrm{N} 60 \mathrm{~W} / 20$ para a seqüência Serra da Malacacheta. Devido à dispersão dos dados, o estereograma da seqüência Juscelândia mostra uma direção NE-SW e duplo caimento, o que pode ser um reflexo do forte anastomosamento de $\mathrm{Sn}$.

Os eixos das dobras Dn, medidos em todas as seqüências mapeadas, possuem uma certa variação na atitude, mas apresentam caimento predominante para W. A média das medidas é $\mathrm{N} 75 \mathrm{~W} / 25$, bem próxima da média de Ln. Nas dobras observadas, verificou-se uma relação de paralelismo entre o seu eixo e a lineação de estiramento, feição muito comum em outros cinturõ es, como por exemplo, na ilha de Syrus, Grécia (Ridley 1986), em Laksefjord, Kalak e Finnmark, no norte da Noruega (Williams 1978, Rhodes \& Gayer 1977), nos Addirondacks, nos EUA (McLelland 1984) e na falha de empurrão de Woodroffe, na Austrália (Bell 1978).

O paralelismo entre as duas lineações pode ser explicado pela rotação do eixo da dobra dentro do plano axial até o seu
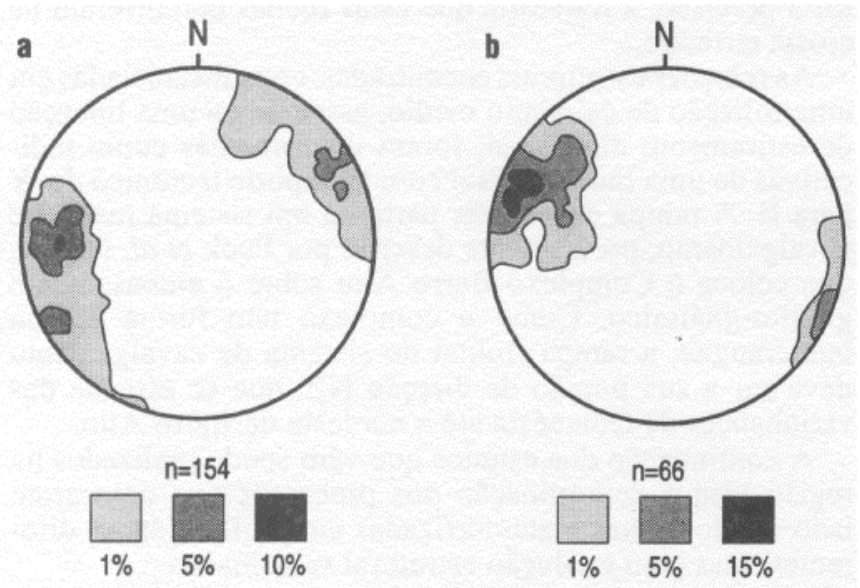

Figura 4 -a. Lineação na seqüência Juscelândia, $n$ - 154, média $N 85 \mathrm{~W} / 25$; b. lineação na seqüencia Serra da Malacacheta, $n=66$, média N60W/20. Diagrama Schmidt Lambert, hemisfério inferior

Figure 4 - a. Ln lineation of the Juscelândia sequence, $n=154$, average $\mathrm{N} 85 \mathrm{~W} / 25 ; \mathrm{b}$. Ln lineation of the Serra da Malacacheta sequence, $\mathrm{n}=66$, average N60W/20. Schmidt Lambert equal area diagram, lower hemisphere posicionamento paralelo à lineação de estiramento, o que torna as dobras acilíndricas (Bell \& Hammond 1984, Rhodes \& Gayer 1977). A mesma feição pode ser explicada com modelo alternativo, onde uma componente direcional é associada à deformação de baixo ângulo. Um campo compressivo é gerado e, por flambagem (buckling), dobras são nucleadas em posição oblíqua ou sub-paralela à direção de transporte. Quando a componente direcional predomina, as dobras são simétricas, cilíndricas e com o eixo paralelo à lineação de estiramento (Coward 1984, Ridley 1986). Esse modelo explica de uma forma mais precisa as relações estruturais observadas na região estudada.

Embora a vergência da foliação e das dobras indique um movimento de empurrão de NNW para SSE, na área de Juscelândia-Cafelândia, a componente direcional parece ser mais expressiva e é marcada por uma forte lineação de estiramento de direção EW. Estruturas assimétricas e porfiroclastos indicam uma movimentação lateral dextral, resultando em um transporte tectônico para leste. A foliação de baixo a médio ângulo com lineação de estiramento direcional, sugere que as estruturas observadas tenham sido geradas em uma rampa lateral a oblíqua.

As Fases $\mathbf{F n + 1}$ e $\mathbf{F n + 2}$ A foliação principal $\mathrm{Sn}$ é afetada por um conjunto de estruturas correlatas, formado por dobras centimétricas, crenulações e fraturas, impresso principalmente nos xistos, embora sem penetratividade expressiva.

As dobras Dn+1 são abertas, assimétricas, com plano axial mergulhando $70^{\circ}$ para WSW e charneiras arredondadas. Não possuem foliação plano axial, embora nos anfibolitos finos exista uma clivagem de fratura com segregações de quartzo e epidoto. A atitude média dos planos axiais é N20W/70SW e dos eixos N50W/35. A relação entre o plano axial e os eixos desta fase indica tratar-se de dobras inclinadas com caimento (Hobbs et al. 1976 figura $4.25 \mathrm{~d}$, p. 180). A figura $5 \mathrm{a}$ mostra as orientações de $\mathrm{Sn}+1 \mathrm{eEn}+1$.

As dobras Dn+2 são muito semelhantes a $\mathrm{Dn}+1$, tendo sido delas separadas em virtude da diferença de orientação dos seus planos axiais, que possuem direção EW e são subverticais, mergulhando tanto para S como para N. A figura 5 b é o estereograma que contém os pólos dos planos axiais $\mathrm{Sn}+2$ e os eixos $\mathrm{En}+2$.

Falhas e Zonas de Cisalhamento Pequenas zonas de cisalhamento empinadas, de caráter rúptil-dúctil (Ramsay
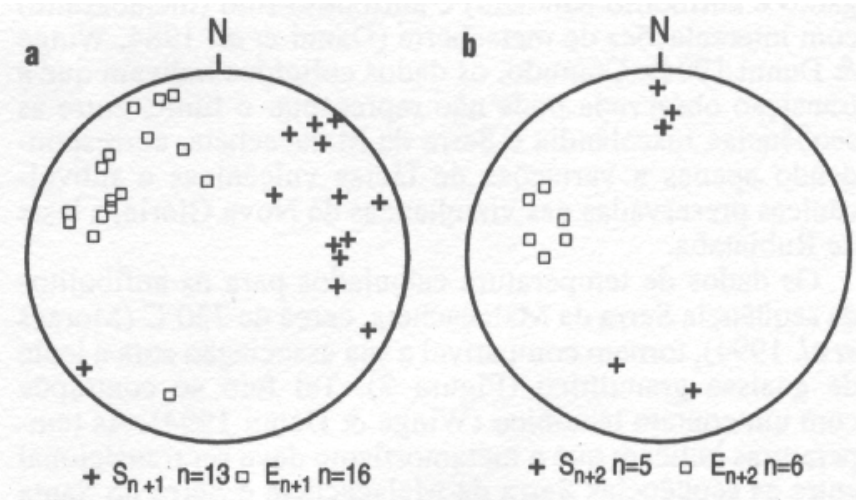

Figura 5-Estereogramas com a. pólos de $\mathrm{Sn}+1$ e atitudes de En+1; b. pólos de $S n+2$ e atitudes de En+2. Diagrama Schmidt Lambert, hemisfério inferior

Figure 5 - Stereographic projections a) $\mathrm{Sn}+1$ poles and $\mathrm{En}+1$ attitudes; b) $\mathrm{Sn}+2$ poles and En+2 attitudes. Schmidt Lambert equal area diagram, lower hemisphere 
1980), estão superpostas a Sn. Segundo as observações feitas, os movimentos são variados, tanto dextrais como sinistrais. A de maior expressão tem o Córrego das Cinzas percorrendo o seu traço a oeste de Juscelândia.

Nas zonas de cisalhamento, os anfibolitos são milonitizados e é gerada uma foliação muito intensa de aspecto anastomosado, com forte heterogeneidade da deformação. A deformação permitiu o acesso e circulação de fluidos, que resultou, através do arrefecimento químico (chemical softening), em assembléias minerais retrometamórficas (com albita, clorita, mica branca, epidoto), facilitando a milonitização.

Considerando as associações mineralógicas presentes nas zonas de cisalhamento, verifica-se que elas ocorreram em condições de temperaturas mais baixas que $\mathrm{Sn}$, dentro do intervalo da fácies xisto verde.

DISCUSSÃO Na área mapeada, a seqüência vulcanosedimentar Juscelândia é constituída, da base para o topo, por: i) (granada) anfibolito fino, com intercalações de metacherte, ii) biotita gnaisse granítico cortado por diques de (granada) anfibolito, iii) muscovita-biotita gnaisse (metavulcânica félsica), iv) (cianita-estaurolita) granada-muscovita-biotita xisto, com intercalações de anfibolito fino, metacherte e xisto feldspático, v) os xistos transicionam, lateral e verticalmente, para filitos com material carboso. Sotoposta à seqüência Juscelândia expõe-se a seqüência Serra da Malacacheta, composta essencialmente por (granada) anfibolito bandado e uma lente de gnaisse granulítico. Mais a sul, aflora a sequiência granulítica Serra de Santa Bárbara, composta por sillimanita-granada quartzito, granulitos félsicos e máficos.

A petrografia revelou que os anfibolitos das seqüências Juscelândia e Serra da Malacacheta são formados por paragêneses distintas, refletindo diferentes condições de metamorfismo. Dados de temperatura e pressão, embora preliminares, mostram que o Complexo Barro Alto é constituído por seqüências metamorfizadas em níveis crustais diferentes. Os resultados indicam uma diferença de cerca de $3 \mathrm{kbar}$ e $200^{\circ} \mathrm{C}$ entre as seqüências Juscelândia e Serra da Malacacheta (Moraes et al 1994). Essa diferença permite inferir uma descontinuidade crustal da ordem de $10 \mathrm{~km}$ entre as referidas seqüências (Moraes et al 1994).

Na região de Ceres-Rubiataba, a oeste da área estudada, é descrita uma passagem transicional entre as referidas seqüências, indicada pela presença de metadiabásio (anfibolito fino com textura diabásica preservada) entre rochas de origem plutônica (olivina gabro coronítico, hiperstênio gabro e anfibolito bandado) e anfibolito fino (metabasalto) com intercalações de metacherte (Danni et al. 1984, Winge \& Danni 1994). Contudo, os dados coligidos indicam que a transição observada pode não representar o limite entre as seqüências Juscelândia e Serra da Malacacheta, correspondendo apenas a variações de fácies vulcânicas e subvulcânicas preservadas nas vizinhanças de Nova Glória, a leste de Rubiataba.

Os dados de temperatura calculados para os anfibolitos da seqüência Serra da Malacacheta, cerca de $720^{\circ} \mathrm{C}$ (Moraes et al. 1994), tornam compatível a sua associação com a lente de gnaisse granulítico (Figura 2). Tal fato se contrapõe com um contato tectônico (Winge \& Danni 1994). As temperaturas indicam que o metamorfismo deve ser transicional entre as seqüências Serra da Malacacheta e Serra de Santa Bárbara.

Nos xistos da seqüência Juscelândia ocorrem variações laterais e verticais, que não foram cartografadas em virtude da falta de continuidade dos afloramentos e da escala adotada. Por exemplo, xistos e filitos carbonosos só afloram na porção nordeste da área mapeada. Com os dados disponíveis, não foi possível determinar se a distribuição tem rela- ção com a história tectono-metamórfica das rochas, ou se reflete alguma característica deposicional da seqüência. A definição das isógradas metamórficas é afetada por essa situação. A isógrada da estaurolita passa a leste da área estudada, e não pôde ser traçada. Embora seja um mineral fácil de ser reconhecido no campo e tenha distribuição areai aparentemente restrita, dentro de xistos sem estaurolita eventualmente ocorrem leitos de composição adequada, onde o mineral está presente. Dentro da área estudada a única isógrada passível de ser traçada foi a da cianita.

Os dados petrográficos indicam condições mínimas da ordem de $550^{\circ} \mathrm{C}$ e 5,5 kbar para o metamorfismo da seqüência Juscelândia, o que está de acordo com os valores calculados para seus anfibolitos (Moraes et al. 1994). As relações texturais observadas nos xistos da seqüência Juscelândia indicam que a ordem de cristalização dos minerais metamórfícos foi granada, estaurolita, cianita, sillimanita e cordierita. Essa sucessão sugere que o metamorfismo ocorreu em uma etapa de pressão mais elevada (soterramento), evidenciada pela cristalização de granada, estaurolita, cianita e sillimanita, seguida por uma etapa de descompressão isotermal (soerguimento), com a cristalização de cordierita como uma fase tardia. A sucessão observada sugere um padrão horário para o metamorfismo.

A associação litológica da seqüência Juscelândia é formada por metassedimentos químicos e pelíticos e rochas metavulcânicas, indicando uma deposição em ambiente subaquoso. A seqüência Serra da Malacacheta é formada por rochas metaplutônicas. No entanto, na área estudada não existem evidências de campo de que estas últimas sejam intrusivas na pilha vulcano-sedimentar Juscelândia. O contato provavelmente é de caráter tectônico pois, os valores de pressão e temperatura calculados mostram uma diferença significativa nas condições do metamorfismo das duas seqüências, cerca de $200^{\circ} \mathrm{C}$ e $3 \mathrm{kbar}$, o que corresponde à supressão de aproximadamente $10 \mathrm{~km}$ de crosta entre as referidas seqüências.

As diferenças petrográficas entre os anfibolitos das seqüências Juscelândia e Serra da Malacacheta, a natureza de seus protolitos e os dados preliminares de temperatura e pressão permitem concluir que o Complexo Barro Alto é constituído por rochas formadas, e subseqüentemente, metamorfizadas em profundidades crustais diferentes. Com os dados disponíveis, não foi possível determinar, com a necessária precisão, a trajetória que estas rochas percorreram na crosta terrestre.

As relações estruturais encontradas, consubstanciadas em uma foliação de caimento médio, associada a uma lineação de estiramento direcional, foram interpretadas como indicativas de uma rampa lateral com transporte tectônico de W para E. A rampa deve fazer parte de um sistema maior de cavalgamento, previamente descrito por Fuck et al. (1981), que coloca o Complexo Barro Alto sobre o embasamento granito-gnáissico. Como o complexo tem forma de um bumerangue, a rampa frontal do sistema de cavalgamento deve ser a sua porção de direção NE, que se estende das vizinhanças de Goianésia até a nordeste de Barro Alto.

A continuação dos estudos que vêm sendo realizados na região visa a determinação dos processos que colocaram lado a lado rochas metamorfizadas em profundidades diferentes, mas com evolução estrutural semelhante.

Agradecimentos $O$ presente trabalho é fruto da dissertação de mestrado do primeiro autor, desenvolvida sob os auspícios do CNPq (Processo 40.1248/89-5). As figuras foram elaboradas com ajuda do Centro de Informática da Universidade de Brasília e de Antônio C.B.C. Vasconcellos. Os autores agradecem a leitura crítica e as sugestões de Mário da Costa Campos Neto e um revisor anônimo, que permitiram o aperfeiçoamento significativo do texto. 


\section{REFERÊNCIAS BIBLIOGRÁFICAS}

ALMEIDA, F.F.M.de 1967. Origem e evolução da Plataforma Brasileira. Rio de Janeiro, DNPM/DGM. 36p (Boletim 241).

ANGEIRAS, A.G. 1968. A faixa de serpentinitos da região central de Goiás. An. Acad. Brás. Ciênc., 40(Suplemento):129-136.

ARAÚJO, S.M. 1986. Petrologia e mineralizações sulfetadas da seqüência vulcano-sedimentar de Palmeirópolis - Goiás. 196p. (Dissertação de Mestrado - IG/UnB)

BAETA JUNIOR, J.D.A.; FIGUEIREDO, A.N.; SOUZA, E.P. \& MELLO, J.C.R. 1972. Projeto Goianésia-Barro Alto. Goiânia. DNPM/CPRM. Relatório inédito VI, $129 \mathrm{p}$.

BARKER, AJ. 1990. Introduction to metamorphic textures and microstructures. Glasgow. Blackie \& Son. 162p

BELL, T.H. 1978. Progressive deformation and reorientation of fold axes in a ductile mylonite zone: the Woodroffe Thrust. Tectonophysics, 44:285-320

BELL, T.H.\& HAMMOND, R.L. 1984. On the internal geometry of mylonite zones./. Geology, 92:667-686.

BROD, J.A. 1988. Geologia das rochas vulcano-sedintentares da região de Indaianópolis, GO e lineamentos adjacentes. 267 p. (Dissertação de Mestrado - IG/UnB).

CARMICHAEL, D.M. 1978. Metamohophic bathozones and bathograds: a measure of the deth of the post-metamorphic uplift and erosion on a regional scale. Am. Jour. Science, 278:769-797.

CORREIA, C.T. 1994. Petrologia do Complexo Máfico-ultramáfico de Cana Brava, Goiás. 151 p. (Tese de Doutorado. IG/USP).

COSTA, L.A.M. \& ANGEIRAS, A.G. 1971. Geosynclinal evolution of the Epi-Baykalian Platform of central Brazil. Geol. Rundschau, 60(2): 1024-1050.

COWARD, M.P. 1984. Major shear zones in the Precambrian crust; exemples from NW Scotland and Southern Africa and their significance. In: KRONER, A. \& GREILING, R. ed. Precambrian Tectonics Illustrated -Stuttgart, p. 207-235.

DANNI, JC.M · FUCK, R A · KUYUMJAN, R M · LEONARDOS, O.H. \& WINGE, M. 1984. O Complexo de Barro Alto na região de CeresRubiataba, Goiás. Rev. Bras. Geoc., 14(2):128-136.

DANNI, J.C.M.; KUYUMJIAN, R.M. 1984. A origem dos anfibolitos basais da seqüência vulcano sedimentar de Juscelândia - Goiás. In: CONGR. BRAS. GEOL., 33. Rio de Janeiro, 1984. Anais... Rio de Janeiro, SBG, v.9, p. 4126-4136.

DANNI, J.C.M. \& LEONARDOS, O.H. 1980. The Niquelândia maficultramafic granulites and gabbro-anortosites-metavolcanic associations (inédito).

DAVIS, G.H. 1984. Structural Geology of Rocks and Regions. New York, John Wiley \& Sons. 492p

FERREIRA FILHO, C.F. \& NALDRETT, A. J. 1991. O Complexo Máfico-Ultramáfico de Niquelândia, Goiás: Novos dados geológicos e estruturais - Implicacões para um modelo tectônico-petrológico. Goiânia, SBG, Núcleo Centro-Oeste. p. 1-26 (Boletim Informativo 14).

FERREIRA FILHO, C.F.; KAMO, S.; FUCK, R.A. \& NALDRETT, A. J. 1993. Zircon andrutile geocronology of the Niquelândia layered mafic and ultramafic intrusion, Brazil: constraints for the timing of magmatism and high-grade metamorphism. Precambrian Research, $68: 241-255$

FIGUEIREDO, A.N. 1978. Geologia e mineralizações do extremo norte do Complexo de Barro Alto, Goiás. 104p. (Dissertação de Mestrado $\mathrm{IG} / \mathrm{UnB})$.

FLEISCHER, R. \& ROUTHIER, P. 1970. Quelques grands themes de la geologic du Brésil - miscellanés geologiques et metallogéniques sur lê Planalto. Sciences de Ia Terre. 15(1):45-102.

FUCK, R.A. 1994. A Faixa Brasília a compartimentação tectônica na Província Tocantins. In: IV SIMPÓSIO DE GEOLOGIA DO CENTRO OESTE, Brasília, 1994. Anais... Brasília, SBG - Núcleo Brasília e Centro Oeste, p.184-187.

FUCK, R.A.; BRITO NEVES. B.B.; CORDANI, U.G. \& KAWASHITA, K 1988. $\mathrm{Rb}$-Sr measurements on metamorphic rocks from the Barro Alto Complex, Goiás, Brazil. INTERNATIONAL CONFERENCE GEOCHEMICAL EVOLUTION OF THE CONTINENTAL CRUST. Pocos de Caldas, p.131-138.

FUCK, R.A.; BRITO NEVES. B.B.; CORDANI, U.G. \& KAWASHITA, K 1989. Geocronologia $\mathrm{Rb}-\mathrm{Sr}$ no Compelxo Barro Alto, Goiás: Evidência de metamorfismo de alto grau e colisão continental há 1300 Ma no Brasil Central. Geochim. Brasiliensis, 3(2): 125-140.

FUCK, R.A.; DANNI, J.C.M.; WINGE, M.; ANDRADE, G.F.; BARREIRA, C.F. LEONARDOS, O.H. \& KUYUMJIAN, R.M. 1981. Geologia da Regão de Goianésia. In: SIMPÓSIO DE GEOLOGIA DO CENTRO OESTE, 1, Goiânia, 1981. Atas... Goiânia, SBG/Núcleo Centro Oeste e Brasília, p. 447-467.

FUCK, R.A.; PIMENTEL, M.M. \& BOTELHO, N.F. 1987. Granitoid rocks in West- Central Brazil: A review. ISGAM. Salvador, Bahia Extended Abstracts, p. 53-59.

GIRARDI.V.A.; RIVALENTI.G. \& SINIGOI, S 1986. The petrogenesis of the Niquelândia layered basic-ultrabasic Complex, central Goiás, Brazil. /. Petrol. 27(3):715-744.
GIRARDI.V.A;; RIVALENTI.G.; SIENA.F. \& SINIGÇI, S. 1981. Precambrian Barro Alto Complex of Goiás, Brazil: Bulk geochemistry and phase equilibria. N. Jb. Miner. Abh. 142(3) :270-291.

HOBBS, B.E.; MEANS, W.D. \& WILLIAMS, P.F. 1976. An Outline of Structural Geology. Singapore, John Wiley \& Sons. $571 \mathrm{p}$

JACOBSON, C.E. 1984. Petrological evidence for the development of refolded folds during a single deformation event. J. Structural Geology, 6(5):563-570.

KUYUMJAN, R.M. \& DANNI, J.C.M. 1991. Geoquímica de anfibolitos da seqüência de Juscelândia, Goiás: implicações geotectônicas. Rev. Bras. Geoc., 21(3):218-223

MAWER, C.K. 1986. What is a Mylonite? Geoscience Canada, 13(1):33-34

McLELLAND, J.M. 1984. The origin of ribbon lineation in the Greenville Province, Ontario, Canada. J. Structural Geology, 6(1/2):147-157.

MILEWSKI, J.P.; PAMPLONA, R.I.; OSTRONOFF, C. \& SARMENTO, C. 1970 . Excursão n ${ }^{\circ}$ : Região de Cana Brava. XXXIV Congr. Brás. Geol. Boi. Esp. n². p. 130-115, Brasília.

MORAES, R. 1992. Metamorfismo e Deformação da Seqüência VulcanaSedimentar Juscelândia, Goiás, e Geoquímica de seus Anfibolitos. 171 p. (Dissertação de Mestrado - IG/UnB).

MORAES, R.; VASCONCELLOS, A.C.B.C. \& FUCK, R.A. 1994. Uma descontinuidade metamórfica no Complexo Barro Alto: Evidência para a sua compartimentacão ? In: IV SIMPOSIO DE GEOLOGIA DO CENTRO OESTE, Brasília, 1994. Anais... Brasília, SBG - Núcleo Brasília e Centro Oeste. p. 135-137.

MOTTA, M.; ARAÚJO, V; MELLO, J.C.R. \& OGUINO, K. 1972. Projeto Niquelândia. Relatório Final. Goiânia, DNPM/CPRM, 6 vol. (inédito)

OLIVEIRA, A. M. \& JOST, H. 1992. Estratigrafia da Seqüência Granulítica do Complexo Barro Alto na região de Goianésia, Goiás. In: CONG. BRAS. GEOL., 37. São Paulo, 1992. Boletim Resumos Expandisos... São Paulo, SBG. v.l, p. 446-447.

PECORA, W.P. \& BARBOSA, A.L.M. 1944. Jazidas de níquel e cobalto de S. José do Tocantins, Estado de Goiás, Brasil.Rio de Janeiro, DNPM/DFPM.69 p. (Boletim. 64).

RAMSAY, J.G. 1980. Shear zone geometry: A review. J. Structural Geology, 2(1/2):83-99.

RHODES, S. \& GAYER, R.A. 1977. Non-cylindrical folds, linear structures in the X direction and mylonite Nappe Complex - Finnmark. Geol. Mag., 114(5):329-408.

RIBEIRO FILHO, W. \& TEIXEIRA, N.A. 1980. Seqüência vulcanosedimentares da borda oeste dos complexos de Niquelândia e Cana Brava.Goiânia, SBG, Núcleo Centro Oeste, p.157-177 (Boletim 10).

RIDLEY, J. 1986. Parallel stretching lineations and fold axes oblique to a shear displacement direction - a model and observations. J. Structural Geology, 8(6):647-653.

STACHE, G.A. 1976. Untersuchugen zur Geologic, Petrographie, Metamorphose und Gênese dês basisch-ultrabasischen massifs von Barro alto, Goiás, Brasilien, Clausthaler Geol. Abh. 24. 149 p.

SUITA, M. T.F.; KAMO, S. L.; KROUGH, T.E.; FYFE, W. S. \& HARTMANN, L.A. 1994. U-Pb ages from the high-grade Barro Alto mafic-ultramafic Complex (Goiás, central Brazil): Middle Proterozoic continental mafic magmatism and the Upper Proterozoic continental collision. In: 8th INTERNATIONAL CONFERENCE ON GEOCHRONOLOGY, COSMOCHRONOLOGY AND ISOTOPE GEOLOGY. Berkeley, 1994. US Geological Survey Circular 1107. Berkeley, p 309.

THAYER, T.P. 1972. Some observatons and problems concerning the peridotites and peridotite-gabro complexes of the Goiás-Belt. In: CONG. BRAS. GEOL., 26. Belém. Boletim Especial. Belém, SBG.

UNIVERSIDADE DE BRASÍLIA 1980. Mapa Geológico do Complexo de Barro Alto. Região de Goianésia. (Inédito).

WILLIAMS, G.D. 1978. Rotation of contemporary folds into X direction during overthrust processes in Laksefjord, Finnriark. Tectonophysics, 48:29-40.

WINGE, M. \& DANNI, J.C.M. 1994. A transicão entre a seqüência gabroanortosítica Serra da Malacacheta (SSM) e os metabasaltos da base sã seqüência Juscelândia (SJ) - Implicações na ênese dos Complexos Barro Alto (CBA), Niquelândia (CN) e Cana Brava (CC), Goiás. In: IV SIMPOSIO DE GEOLOGIA DO CENTRO OESTE, Brasília, 1994. Anais... Brasília, SBG - Núcleo Brasília e Centro Oeste. p.131-134.

WISE, D.U.: DUNN, D.E.; ENGELDER, J.T.; GEISER, P.A.; HATCHER, R.D.; KISH, S.A.; ODOM, A.L. \& SCHAMEL, S. 1984. Fault-related rocks: suggestions for terminology. Geology, 12:391-394.

YARDLEY, B.W.D. 1989. An introduction to metamorphic Petrology. New York, Longman/John Wiley \& Sons. 248 p.

MANUSCRITO A819

Recebido em 6 de setembro de 1994 Revisão do autor em 6 de julho de 1995 Revisão aceita em 3 de agosto de 1995 